\title{
Uncertainty assessment of carbon dioxide concentration measurement with a cavity ring-down spectrometer
}

\author{
Xing Wang ${ }^{1, a}$ and Zeyi Zhou ${ }^{1, b}$ \\ ${ }^{1}$ National Institute of Metrology, No.18, Bei San Huan Dong Lu, Chaoyang District, Beijing, \\ 100013, China \\ awangxingnim@outlook.com, b'zhouzy@nim.ac.cn
}

\begin{abstract}
Keywords: carbon dioxide, cavity ring-down spectrometer, calibration gas mixtures, uncertainty assessment

Abstract. Cavity ring-down (CRD) spectroscopy are attracting widespread interest in gas measurements, especially for gas metrology. However, there still needs more research about its metrological traceability to develop it as a primary method. We developed and assessed a high-sensitive cavity ring-down spectrometer (CRDS) by using carbon dioxide $\left(\mathrm{CO}_{2}\right)$ calibration gas mixtures. It can maintain high sensitivity, linearity and precision over changing temperature conditions. So we utilized the analyzer to present a detailed assessment method of result uncertainty.
\end{abstract}

\section{Introduction}

CRD spectroscopy is a direct absorption technique and has received much attention in recent years due to its higher sensitivity than that of conventional absorption spectroscopy. The advantage of the technique can be demonstrated by two aspects: insensitivity to the fluctuations of light source intensity and extreme long effective path lengths. In last decades, much research has been focused on its application in gas measurements, especially for green house gases, such as $\mathrm{CO}_{2}$, methane $\left(\mathrm{CH}_{4}\right)$, and water vapor [1-8].

CRD spectroscopy has attracted considerable interest in gas metrology as well. As for many metrology institutes and laboratories, some commercial equipment has played an important role in some studies and comparisons [9,10]. Taking the international comparison CCQM-K82 [11] as an example, influence of air on $\mathrm{CH}_{4}$ standards was investigated by a combination method of Gas chromatography with flame ionization detection (GC-FID) and CRDS [12]. Moreover, CRD spectroscopy analyzer is utilized to monitor gas concentration in International Bureau of Weights and Measures (BIPM) formaldehyde primary facility [13].

In general, infrared spectrometry techniques can be used to analyze the amount-of-substance fractions to species in gas mixtures, and they are calibration-free in principle because of the results traceable to the SI units [14]. However, only small amount of work has been done about traceability of infrared spectrometry techniques, and almost all of them utilized traditional spectrometers instead of CRDS. For example, in 2010, a comparison embedded in EURAMET 934 project was conducted by using calibration-free infrared laser-spectrometries [15]. However, although protocol of the project proposed CRDS as more sensitive technique to apply, the participants finally selected conventional tunable diode laser absorption spectroscopy (TDLAS). Besides, in the comparison CCQM-P110, conventional Fourier Transform Infrared Spectroscopy 
(FT-IR) acted as an absolute method to evaluate the level of comparability of laboratories' nitrogen dioxide $\left(\mathrm{NO}_{2}\right)$ measurements [16].

As a valuable and sensitive infrared spectroscopy technique, CRDS has the potential to be primary methods [14]. However, there remains a need of more studies about the metrological traceability of gas measurements results by using CRDS. In present work, we developed a cavity ring-down spectrometer and assessed the system by using $\mathrm{CO}_{2} /$ air calibration gas mixtures. With analysis of major impact factors and sources of uncertainty, the uncertainty of measurement results was given.

\section{Experimental setup}

A diagram of the experimental setup is presented in Fig. 1. As shown in the diagram, the basic components making up the system are a laser, a high speed optical switch, a high finesse optical cavity $(47.508 \mathrm{~cm})$ with two high reflectivity mirrors(>99.99\%), a photo-detector and a temperature controller. Operationally, the near-infrared laser beam from a distributed feedback diode laser (DFB) is sent into an optical isolator (OI), and then selected by an acoustic optical modulator (AOM) which serves as the optical switch. In addition, a set of lens are used to couple the laser beam into the ring-down cavity. The light intensity inside the cavity will build up and partly leak out, and the leaking laser is monitored by the photo-detector.

The principle of gas concentration measurement by CRDS is mainly based on the determination of optical absorbance of the sample in a high-fineness optical cavity [17,18]. A ring-down event will be recorded by a digitizer installed in a personal computer with measuring the light intensity of leaking laser, which decays exponentially with a time constant $\tau$. The optical absorbance is related to the decay time through the equation

$$
\frac{1}{c \tau(\lambda)}=\frac{1}{c \tau_{0}}+\alpha(\lambda)
$$

where $\mathrm{c}$ is the speed of light, $\lambda$ is the wavelength, $\alpha(\lambda)$ is absorption coefficient, and $\tau$ and $\tau_{0}$ are the decay time of the cavity with and without sample. Therefore, the concentration $\left(\chi_{\mathrm{co} 2}\right)$ can be got by the percentage of the partial pressure of $\mathrm{CO}_{2}$, which can be showed by

$$
\chi_{\mathrm{CO}_{2}}=\frac{\mathrm{p}_{\mathrm{CO}_{2}}}{\mathrm{P}_{\text {total }}}=\frac{\int \alpha(\lambda) \mathrm{d} \lambda}{\mathrm{S} \mathrm{P}_{\mathrm{tot}}} \frac{\mathrm{RT}}{\mathrm{N}_{\mathrm{A}}} .
$$

where $\mathrm{S}$ is the line density, $\mathrm{PcO}_{2}$ is the partial pressure of $\mathrm{CO}_{2}, \mathrm{P}_{\text {total }}$ is the total pressure of sample, $\mathrm{N}_{\mathrm{A}}$ is the Avogadro constant, $\mathrm{R}$ is the molar gas constant, and $\mathrm{T}$ is the temperature of the gas sample. 


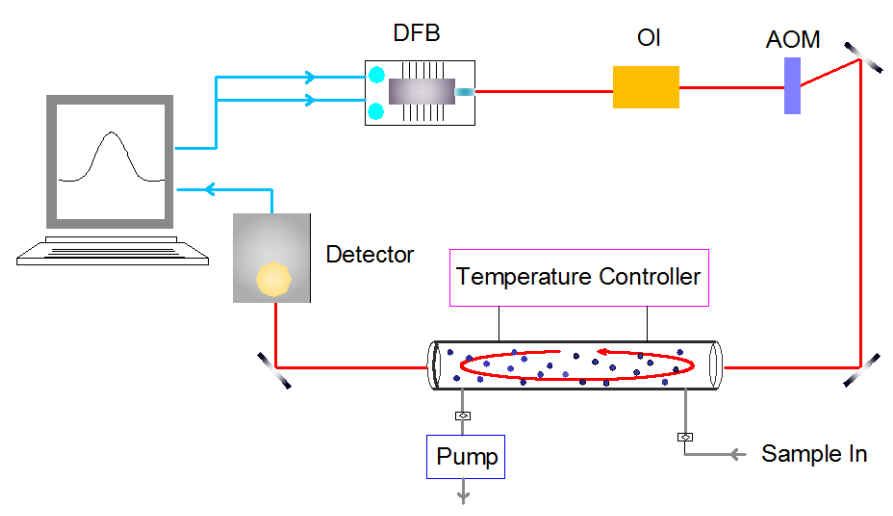

Fig. 1 The configuration of CRDS setup

\section{Results and discussion}

\section{Evaluation of the spectrometer.}

A. Determination of minimum detectable concentration.

In order to get the detection limit, the $\mathrm{CO}_{2}$ spectrum near $6242.67 \mathrm{~cm}^{-1}$ has been repeatedly measured for about $3 \mathrm{~h}$ and 300 spectra were recorded. As shown in Fig. 2, we averaged the spectra obtained from the measurements of $588.67 \mu \mathrm{mol} / \mathrm{mol} \mathrm{CO}_{2}$ calibration gas $(296.95 \mathrm{~K}$, 337.10 Torr). Minimum detectable absorption coefficient can be obtained by residual analysis $\left(\alpha_{\min }=1 \times 10^{-10} \mathrm{~cm}^{-1}\right)$.

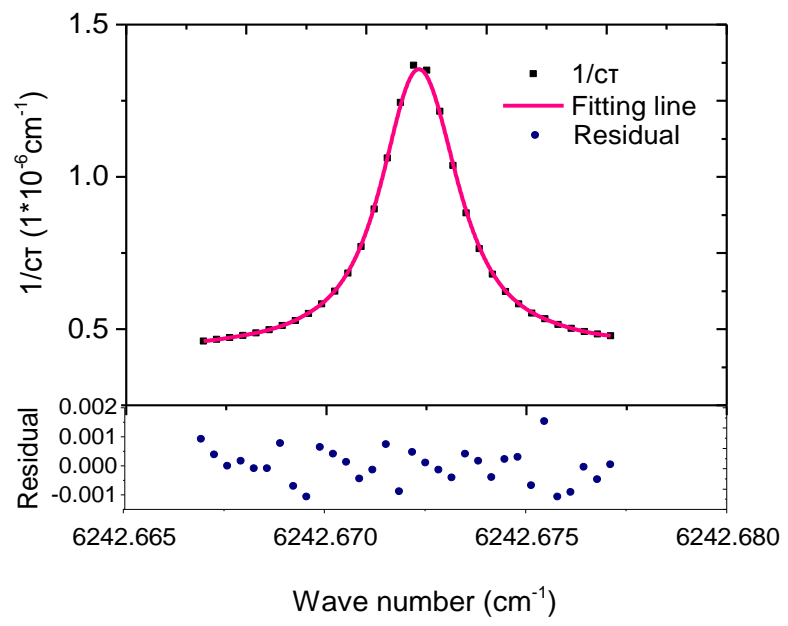

Fig. 2 An absorption line of $6242.67 \mathrm{~cm}^{-1}$ measured by the CRDS

In general, the detection limit $\left(\chi_{\min }\right)$ is proportional to $\alpha_{\min }$ :

$$
\chi_{\min }=\frac{\alpha_{\min }}{S P_{\text {tot }} \phi_{0}} \frac{R T}{N_{A}}
$$

where $\varphi_{0}$ is the height of line profile and the line density $S$ of chosen absorption line is 1.636 $\times 10^{-23} \mathrm{~cm}^{-1} /\left(\right.$ molecule $\left.* \mathrm{~cm}^{-2}\right)$ [19]. Because the chosen line profile is Lorentz, the height $\varphi_{0}$ can be obtained by [20]:

$$
\phi_{0}=\frac{2}{\omega_{L} \pi} \text {. }
$$




$$
\varpi_{L}=P_{t o t} \sum_{\mathrm{i}} 2 \chi_{i} \gamma_{i}(T)
$$

where $\omega_{\mathrm{L}}$ is the full width at half maximum and $\gamma_{\mathrm{i}}$ is the coefficient of pressure broadening. In this experiment, $\gamma_{\mathrm{i}}$ includes air-pressure broadening coefficient $\left(0.07270 \mathrm{~cm}^{-1} / \mathrm{atm}\right)$ and self-broadening coefficient $\left(0.098 \mathrm{~cm}^{-1} / \mathrm{atm}\right)$. Therefore, the minimum detection concentration is $1.31 \mathrm{ppbv}$ in 337.01 Torr, which shows the high sensitivity of the analyzer.

\section{B. Measurement linearity}

The linearity of the analyzer was obtained by testing a series of $\mathrm{CO}_{2}$ calibration gas mixtures prepared by gravimetric method: $986.14 \mu \mathrm{mol} / \mathrm{mol}, 802.95 \mu \mathrm{mol} / \mathrm{mol}, 588.67 \mu \mathrm{mol} / \mathrm{mol}, 517.01$ $\mu \mathrm{mol} / \mathrm{mol}, 356.50 \mu \mathrm{mol} / \mathrm{mol}, 381.90 \mu \mathrm{mol} / \mathrm{mol}, 247.48 \mu \mathrm{mol} / \mathrm{mol}$, and $100.59 \mu \mathrm{mol} / \mathrm{mol}$ respectively. Specially, the tested $\mathrm{CO}_{2}$ concentration included the range typically found in ambient air, normally 300-800 $\mu \mathrm{mol} / \mathrm{mol}$.

The analyzer has a linear response with concentration as illustrated in Fig. 3. The linear coefficient of measured concentration with calibration gas is 0.99674 , and we compared it with the result 0.99988 of Picarro G2301 using same series of calibration gas. The comparison indicates that the linearity of analyzer has achieved commercial level.

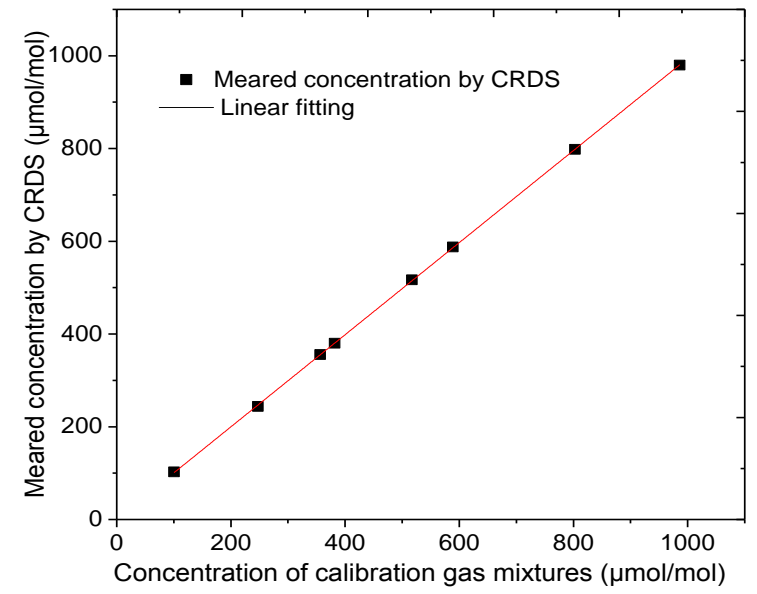

Fig. 3 CRDS analyzer measurements against $\mathrm{CO}_{2}$ calibration gas with assigned value

\section{Impacts of temperature}

In this work, the influence of temperature on results was observed by testing $517.01 \mu \mathrm{mol} / \mathrm{mol}$ $\mathrm{CO}_{2}$ calibration gas by CRSD at different temperatures. It can be seen from table 1 that the measured concentration decreases with the rise of temperature, while the relative standard deviation (RSD) increases. RSD shows the dispersion of a set of data values, therefore the temperature will impact on accuracy of measurement to some extent.

Table 1 Conditions and results of $\mathrm{CO}_{2}$ measurements by CRDS at different temperatures.

\begin{tabular}{cccccc}
\hline $\begin{array}{c}\text { Concentration of } \\
\text { calibration gas } \\
(\mu \mathrm{mol} / \mathrm{mol})\end{array}$ & $\begin{array}{c}\text { Temperature } \\
(\mathrm{K})\end{array}$ & $\begin{array}{c}\text { Pressure } \\
(\text { Torr })\end{array}$ & $\begin{array}{c}\text { Measured } \\
\text { concentration } \\
(\mu \mathrm{mol} / \mathrm{mol})\end{array}$ & RSD & $\begin{array}{c}\int \alpha(\lambda) \mathrm{d} \lambda \\
\left(\mathrm{cm}^{-2}\right)\end{array}$ \\
\hline 517.01 & 303.23 & 329.80 & 516.85 & 0.032 & 0.0901 \\
517.01 & 308.53 & 333.09 & 516.40 & 0.049 & 0.0896 \\
517.01 & 313.23 & 328.11 & 515.99 & 0.066 & 0.0893 \\
517.01 & 321.21 & 333.71 & 515.78 & 0.078 & 0.0890 \\
517.01 & 332.44 & 330.50 & 515.42 & 0.104 & 0.0888 \\
\hline
\end{tabular}


The change of temperature mainly affects line intensity (S) and the results of $\int \alpha(\lambda) \mathrm{d} \lambda$. According to the previous work and equations [21-24], the increase of the $T$ will result in the decrease of $S$, which means the absorption of the gas will reduce. Furthermore, table 1 shows a falling tendency of $\int \alpha(\lambda) \mathrm{d} \lambda$ with the increase of temperature, and it is due to the change of broadening effects. Increasing the temperature causes more significant heating effects and Doppler line broadening. Therefore, the changes of $\mathrm{S}$ and $\int \alpha(\lambda) \mathrm{d} \lambda$ finally lead to the decreases of measured results.

According to table1, the relationship of $\mathrm{T}$ and measured concentration is $\mathrm{y}=-0.0466 \mathrm{x}+530.79$. Because of the temperature controller, the maximal deviation of temperature is $0.3 \%$ after the temperature parameter is set. Therefore, the change of measured results caused by temperature fluctuation less than $0.041 \mu \mathrm{mol} / \mathrm{mol}$, which indicates good accuracy and stability of the system over changing temperature conditions.

\section{Assessment of the uncertainty.}

Measured results of $588.67 \mu \mathrm{mol} / \mathrm{mol} \mathrm{CO}_{2}$ calibration gas mixtures (296.95 K, 336.01Torr) are utilized to illustrate the general uncertainty evaluation method of CRDS. In the first place, we analyzed the sources of uncertainty, and the main sources are S, T, P and the results of $\int \alpha(\lambda) \mathrm{d} \lambda$ ( see Eq. 2).

In the experiment, maximal deviation of pressure and temperature is $1 \%$ and $0.3 \%$ respectively. According to previous studies [24], the change of S caused by fluctuation of $\mathrm{T}$ can be showed by the equation

$$
\frac{1}{\mathrm{~S}} \frac{\mathrm{dS}}{\mathrm{dT}}=-\frac{1}{\mathrm{Q}(\mathrm{T})} \frac{\mathrm{dQ}(\mathrm{T})}{\mathrm{dT}}+\frac{\mathrm{hcE}}{\mathrm{k}_{\mathrm{B}} \mathrm{T}^{2}}-\frac{\mathrm{hc}_{\mathrm{V}_{0}}}{\mathrm{k}_{\mathrm{B}} \mathrm{T}^{2}} \frac{1}{\exp \left(\frac{\mathrm{hc}_{\mathrm{V}_{0}}}{\mathrm{k}_{\mathrm{B}} \mathrm{T}}\right)-1} .
$$

$\mathrm{Q}(\mathrm{T})$ is partition function associated with the temperature:

$$
\mathrm{Q}(\mathrm{T})=\mathrm{a}+\mathrm{b} \times \mathrm{T}+\mathrm{d} \times \mathrm{T}^{2}+\mathrm{e} \times \mathrm{T}^{3} .
$$

where detailed parameters of Eq. 6 and Eq. 7 are listed in the table 2 [25]. After calculation, the deviation of $\mathrm{S}$ can be acquired (-0.634\%).

\begin{tabular}{|c|c|c|c|c|c|}
\hline Parameter & Meaning & Value & Parameter & Meaning & Value \\
\hline $\mathrm{K}_{\mathrm{B}}$ & $\begin{array}{c}\text { Boltzmann } \\
\text { constant }\end{array}$ & $1.3807 \times 10^{-23}$ & $\mathrm{a}$ & $\begin{array}{c}\text { Polynomial } \\
\text { coefficient }\end{array}$ & -1.3617 \\
\hline $\mathrm{v}_{\mathrm{O}}$ & $\begin{array}{c}\text { Wave } \\
\text { number }\end{array}$ & $\begin{array}{c}6242.6722 \\
\mathrm{~cm}^{-1}\end{array}$ & $\mathrm{~b}$ & $\begin{array}{c}\text { Polynomial } \\
\text { coefficient }\end{array}$ & 0.9490 \\
\hline $\mathrm{E}$ & $\begin{array}{l}\text { Energy of } \\
\text { lower state }\end{array}$ & $\begin{array}{c}163.8684 \\
\mathrm{~cm}^{-1}\end{array}$ & d & $\begin{array}{c}\text { Polynomial } \\
\text { coefficient }\end{array}$ & $-6.9259 \times 10^{-4}$ \\
\hline $\mathrm{h}$ & $\begin{array}{c}\text { Planck } \\
\text { constant }\end{array}$ & $\begin{array}{c}6.6261 \times 10^{-34} \\
\mathrm{~J} \cdot \mathrm{s}\end{array}$ & $\mathrm{e}$ & $\begin{array}{c}\text { Polynomial } \\
\text { coefficient }\end{array}$ & $2.5974 \times 10^{-6}$ \\
\hline
\end{tabular}

Table 2 Parameters for the Eq. 6 and Eq. 7.

Standard uncertainty of $\int \alpha(\lambda) \mathrm{d} \lambda$ can be calculated from experiment data of Eq. 1 by using Bessel formula, and Fig. 4 shows the results distribution of $\int \alpha(\lambda) \mathrm{d} \lambda$. 


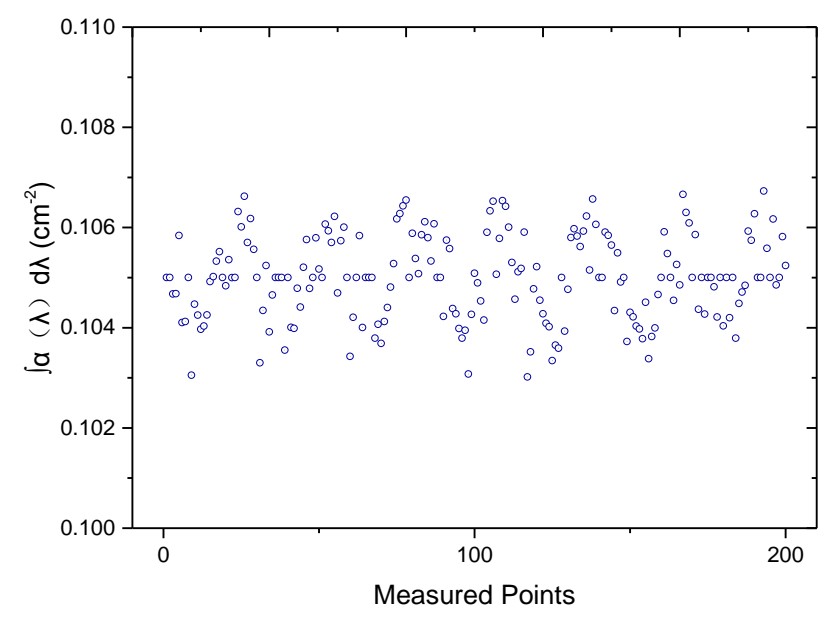

Fig. 4 Measured results distribution of $\int \alpha(\lambda) \mathrm{d} \lambda$

Furthermore, the standard uncertainty of measurement result can be derived from Eq. 2 and expressed as Eq. 8. In the meantime, the budget of standard uncertainty is listed in table 3[26].

$$
\begin{aligned}
& \mathrm{u}^{2}\left(\chi_{\mathrm{CO}_{2}}\right)=\sum_{\mathrm{i}=1}^{\mathrm{n}} \mathrm{A}_{\mathrm{i}}^{2} \mathrm{u}^{2}\left(\mathrm{x}_{\mathrm{i}}\right)=\left(\frac{\mathrm{RT}}{\mathrm{SP}_{\text {total }} \mathrm{N}_{\mathrm{A}}}\right)^{2} \mathrm{u}^{2}\left(\int \alpha(\lambda) \mathrm{d} \lambda\right)+\left(\frac{\int \alpha(\lambda) \mathrm{d} \lambda}{\mathrm{SP}_{\text {total }}} \frac{\mathrm{T}}{\mathrm{N}_{\mathrm{A}}}\right)^{2} \mathrm{u}^{2}(\mathrm{R})+\left(\frac{\int \alpha(\lambda) \mathrm{d} \lambda}{\mathrm{SP}_{\text {total }}} \frac{\mathrm{R}}{\mathrm{N}_{\mathrm{A}}}\right)^{2} \mathrm{u}^{2}(\mathrm{~T}) \\
& +\left(\frac{-\int \alpha(\lambda) \mathrm{d} \lambda}{\mathrm{S}^{2} \mathrm{P}_{\text {total }}} \frac{\mathrm{TR}}{\mathrm{N}_{\mathrm{A}}}\right)^{2} \mathrm{u}^{2}(\mathrm{~S})+\left(\frac{-\int \alpha(\lambda) \mathrm{d} \lambda}{\mathrm{SP}_{\text {total }}^{2}} \frac{\mathrm{TR}}{\mathrm{N}_{\mathrm{A}}}\right)^{2} \mathrm{u}^{2}\left(\mathrm{P}_{\text {total }}\right)+\left(\frac{-\int \alpha(\lambda) \mathrm{d} \lambda}{\mathrm{SP}_{\text {total }}} \frac{\mathrm{TR}}{\mathrm{N}_{\mathrm{A}}^{2}}\right)^{2} \mathrm{u}^{2}\left(\mathrm{~N}_{\mathrm{A}}\right)
\end{aligned}
$$

\begin{tabular}{|c|c|c|c|}
\hline $\begin{array}{l}\text { Sources of } \\
\text { uncertainty }\end{array}$ & Distribution type & Standard uncertainty $\left(\mathrm{u}\left(\mathrm{x}_{\mathrm{i}}\right)\right)$ & $\begin{array}{l}\text { Coefficient of } \\
\text { sensitivity }\left(A_{j}\right)\end{array}$ \\
\hline S & $\begin{array}{l}\text { Rectangular } \\
\text { Distribution }\end{array}$ & $\begin{array}{c}5.67 \times 10^{-28} \\
\mathrm{~m}^{-1} /\left(\text { molecule }^{*} \mathrm{~m}^{-2}\right)\end{array}$ & $-3.20 \times 10^{19}$ \\
\hline $\mathrm{P}_{\text {total }}$ & $\begin{array}{l}\text { Rectangular } \\
\text { Distribution }\end{array}$ & $290.27 \mathrm{~Pa}$ & $-1.04 \times 10^{-10}$ \\
\hline $\mathrm{T}$ & $\begin{array}{l}\text { Rectangular } \\
\text { Distribution }\end{array}$ & $0.51 \mathrm{~K}$ & $1.76 \times 10^{-8}$ \\
\hline $\int \alpha(\lambda) \mathrm{d} \lambda$ & Normal Distribution & $1.04 \times 10^{-8} \mathrm{~m}^{-2}$ & 0.50 \\
\hline $\mathrm{R}$ & Normal Distribution & $3.33 \times 10^{-4} \mathrm{~Pa} \cdot \mathrm{m}^{3} / \mathrm{mol}$ & $6.30 \times 10^{-7}$ \\
\hline $\mathrm{N}_{\mathrm{A}}$ & Normal Distribution & $3.33 \times 10^{20} \mathrm{~mol}^{-1}$ & $-8.70 \times 10^{-30}$ \\
\hline
\end{tabular}

Table 3 Budget of standard uncertainty

Combined standard uncertainty is calculated as below:

$$
\mathrm{u}\left(\chi_{\mathrm{Co}_{2}}\right)=\sqrt{\sum_{\mathrm{i}=1}^{\mathrm{n}} \mathrm{A}^{2}{ }_{\mathrm{i}} \mathrm{u}^{2}\left(\mathrm{x}_{\mathrm{i}}\right)}=0.037 \mu \mathrm{mol} / \mathrm{mol} \text {. }
$$

In the last place, expanded uncertainty with $95 \%$ confidence (the coverage factor $k=2$ ) can be obtained by the equation

$$
\mathrm{U}\left(\chi_{\mathrm{co}_{2}}\right)=\mathrm{k} \times \mathrm{u}\left(\chi_{\mathrm{co}_{2}}\right)=0.074 \mu \mathrm{mol} / \mathrm{mol} \text {. }
$$




\section{Conclusions}

A high sensitive cavity ring-down analyzer capable of performing measurement of atmospheric levels of carbon dioxide is described and assessed. The results show that it can maintain high sensitivity, linearity and precision over changing environmental conditions. Moreover, for studying the metrological traceability of gas measurements results by using CRDS, detailed assessment method and budget of uncertainty was given. The procedure of evaluating the result uncertainty can show the sources of correction and study the influence of major parameters by using CRDS.

\section{Acknowledgement}

The work is funded by Key Projects in the National Science and Technology Pillar Program during the Twelfth Five-year Plan Period.

\section{References}

[1] Huilin Chen, J. Winderlich, C. Gerbig, Annette Filges, C. Rella and Eric Crosson, Atmos. Meas.Tech. Vol. 75-386 (2010), p.3.

[2] Prado-P'erez AJ, Rodr'1guez-Ar'evalo J and D'iaz-Teijeiro MF, Meas. Sci. Technol. 015801 (11pp) (2014), p.25

[3] H. Nara, H. Tanimoto, Y. Tohjima, H. Mukai, Y. Nojiri, K. Katsumata and C. W. Rella, Atmos. Meas. Tech. Vol. 2689-2701 (2012), p.5.

[4] Bing Chen, Yu R Sun, Zeyi Zhou, Jian Chen, Anwen Liu and Shuiming Hu, Appl. Optics Vol. $7716-7723$ (2014), p.53.

[5]Bing Chen, Peng Kang, Jian-ying Li, Xiao-lei He, An-wen Liu and Shui-ming Hu, Chinese J. Chem. Phys. Vol. 6-10 (2015) , p.28.

[6] Crosson ER, A cavity ring-down analyzer for measuring atmospheric levels of methane, carbon dioxide, and water vapor Appl. Phys. B-Lasers O. Vol. 403-408 (2008), p.92.

[7] Jongma RT, MGHB, Holleman I and Meijer G, Rev. Sci. Instrum. Vol. 2821-2827 (1995), p.66.

[8] John B. Dudek, Peter B. Tarsa , Armando Velasquez, Mark Wladyslawski, Paul Rabinowitz and Kevin K. Lehmann, Anal. Chem. Vol. 4599-4605 (2003), p.75.

[9] Abe H and Kitano H Sensor Actuat. A-Phys. Vol. 723-729 (2007), p.136

[10] Lin H, Reed Z D, Sironneau V T and Hodges J T, J. Quant. Spectrosc. Ra. Vol. 11-20 (2015), p.161.

[11]Flores, E., Viallon, J., Choteau, T., Moussay, P., Wielgosz, R. I., Kang, N., ... \& Wu, H., Metrologia (2014).

[12]Edgar Flores, George C. Rhoderick, Joële Viallon, Philippe Moussay, Tiphaine Choteau, Lyn

Gameson, Franklin R. Guenther and Robert Ian Wielgosz, Anal. Chem. Vol. 3272-3279 (2015), p. 87.

[13] Information on http://www.bipm.org/en/bipm/chemistry/gas-metrology/formaldehyde-comparisons.html

[14] Milton M J T and Quinn T J, Metrologia Vol. 289-296 ( 2001), p.38.

[15] Information on http://www.euramet.org/fileadmin/docs/projects/934_METCHEM_Interim_Report.pdf

[16] Information on 
http://www.euramet.org/Media/docs/projects/934_METCHEM_Comparison_Report.pdf

[17] Law B L, Cavity-ringdown spectroscopy-An ultratrace-absorption measurement technique, Appl. Spectrosc. Vol. 54 p.162A (2000)

[18] Berden G, Peeters R and Meijer G, Int. Rev. Phys. Chem. Vol. 565 -607 (2000), p.19.

[19] Rothman, L. S., Gordon, I. E., Babikov, Y., Barbe, A., Benner, D. C., Bernath, P. F., ... \& Campargue, A. J. Quant. Spectrosc. Radiat. Transfer Vol. 4-50 (2013), p.130

[20] Zhou X, Ph.D. Dissertation, Stanford University, Diode laser absorption sensors for combustion control (2005)

[21] Penner S and Landshoff R, Phys. Today Vol. 38-40 (2009), p.13.

[22] Madden RP, J. Chem. Phys. Vol. 2083-97 (1961), p.35.

[23] Kiehl J and Ramanathan V, J. Geophys. Res. Oceans vol. 5191-202 (1983), p.88.

[24] Šimečková M, Jacquemart D, Rothman LS, Gamache RR and Goldman A, J. Quant. Spectrosc. Ra. Vol. 130-55 (2006), p.98.

[25] Gamache R, Kennedy S, Hawkins R and Rothman L, J. Mol. Struct. Vol. 407-25 (2000), p.517.

[26] Zhou X and Zhou Z Y, Acta Metro. Sin. Vol.33-2 (2012), p.178. (in Chinese) 